\title{
The different encapsulants of lileum leaves (Clerodendrum Minahassae L) and Avocado Seed (Persea Americana Mill) extraction on Physical Quality and Microscopic Structure
}

\author{
Mursye Nataly Regar $^{2}$ Yuli Frita Nuningtyas ${ }^{1}$, Muhammad Halim Natsir ${ }^{1^{*}}$ \\ ${ }^{1}$ Faculty of Animal Science, University of Brawijaya, Malang 65145, Indonesia \\ ${ }^{2}$ Doctoral student, Faculty of Animal Science, University of Brawijaya, Malang 65145, \\ Indonesia
}

\begin{abstract}
This research aimed to examine the differences encapsulant of leilem leaves and avocado seed $(1: 1)$ using a microwave oven to the microcapsule product physical quality and microscopic structure. The method was used laboratory experimental with 5 different encapsulants consist of gum arab (A1), whey (A2), chitosan (A3), maltodextrin (A4) and zeolit (A5) with 4 replications in every treatment, respectively. The Variables observed in this research consist of physical quality (dry matter, density, yield, solubility of solids) and microscopic structure. The data of physical quality was evaluate the size and structure, then the microscopic structure was analysed by analysis of variance (ANOVA) of the experiment using Completely Randomized Design (CRD). The results showed that the use of different encapsulates showed a significant $(\mathrm{P}<0.05)$ effect on density and the solubility of solids in the product but it were not significant effect on dry matter and yield. Furthermore, different encapsulants also showed significantly different on the microscopic structure. Therefore, it can be concluded that the encapsulation process of the mixed extract of leilem leaves and avocado seeds using a microwave oven and chitosan encapsulation can produce the best physical quality and microscopic structure.
\end{abstract}

\section{Introduction}

The régulation of Ministry of Agriculture, number 14/2017 article 16 paragraph 1, feed and feed additives must not contain Antibiotic Growth Promoter (AGP). Therefore, the solution to overcome these problems is to use natural feed additives or Natural growth promoters (NGP). NGP can be obtained from herbal plants and an agricultural by-product as feed additives for poultry.

Leilem (Clerodendrum minhassae L.) is a widely grown plant used as food and traditional medicine in Minahasa, North Sulawesi Province. Leilem plant is part of the genus Clerodendrum L. (family: Lamiaceae) which contains bioactive compounds such as phenols, flavonoids, terpenoids, and steroids[1]. This is effective as an antimicrobial compound against microorganisms[2]. The avocado industry also produces waste in the

*Corresponding author: emhanatsir@ub.ac.id 
form of avocado seeds. Avocado seeds are rich in polyphenols with potent antioxidant and antimicrobial properties [3] such as carotenoids, minerals, phenolics, vitamins, fatty acids, glycosides, phenols, alkaloids, cyanogenic, steroids, tannins and saponins [4].

This research aimed to examine the differences encapsulant of leilem leaves and avocado seed $(1: 1)$ using a microwave oven to the microcapsule product physical quality and microscopic structure

\section{Materials and methods}

This research was conducted in Animal Nutrion Laboratory, Animal Science Faculty Universitas Brawijaya, Malang, East Java started from July 15 to August 16, 2021.

\subsection{Materials}

The material used in this research were gum arab, whey, chitosan, maltodextrin and zeolit. The tools and materials used during the study were microwave oven extraction and microwave oven encapsulation.

\subsection{Methods}

The method was used laboratory experimental with 5 different encapsulants consist of gum arab (A1), whey (A2), chitosan (A3), maltodextrin (A4) and zeolit (A5) with 4 replications in every treatment, respectively. The variables observed in this research consist of physical quality (dry matter, density, yield, solubility of solids) and microscopic structure.

Encapsulation process of leilem leaves and avocado seed are at ratio $1: 1$ as many as $25 \%$ as encapsulant. At the same time, leilem leaves and avocado seed extract and encapsulant treatments are stirred into ultrasonic mixing. Furthermore, this product put into a microwave with low temperature for 4 minutes. Temperature of microwave is controlled at less than $60{ }^{\circ} \mathrm{C}$ with thermostat and blower. The protected leilem leaves and avocado seed extract is cooled in the tray. Finished protected leilem leaves and avocado seed are milled and packed ${ }^{[5]}$.

The structure of the encapsulated product was evaluated by Scanning electron microscopy (SEM) type TM 3000 with 500x magnification. 


\subsection{Data analysis}

Data were analyzed using one-way ANOVAs based on Completely Randomized Design, if there was significant effect then continued with Duncan Multiple Range.

\section{Results and discussion}

The results showed that the used of differences encapsulant in the encapsulation process showed highly significant $(\mathrm{P}<0.05)$ effect on physical quality of encapsulation product were dry matter, density, yield, solubility of solids completely can be seen in Table 1 .

Table 1. Effect of differences encapsulant in the encapsulation process of leilem leaves and avocado seed extract with using a microwave oven on the product physical quality

\begin{tabular}{|l|c|c|c|c|c|}
\hline \multirow{2}{*}{ Variables } & \multicolumn{5}{|c|}{ Treatments } \\
\cline { 2 - 6 } & $\mathrm{A} 1$ & $\mathrm{~A} 2$ & $\mathrm{~A} 3$ & $\mathrm{~A} 4$ & $\mathrm{~A} 5$ \\
\hline Dry matter $(\%)$ & $92.02 \pm 0.06$ & $92.72 \pm 0.16$ & $93.48 \pm 0.03$ & $93.50 \pm 0.06$ & $91.56 \pm 0.08$ \\
\hline Density $\left(\mathrm{g} / \mathrm{cm}^{3}\right)$ & $0.36 \pm 0.01^{\mathrm{a}}$ & $0.39 \pm 0.01^{\mathrm{b}}$ & $0.35 \pm 0.01^{\mathrm{a}}$ & $0.43 \pm 0.01^{\mathrm{c}}$ & $0.42 \pm 0.01^{\mathrm{bc}}$ \\
\hline Yield (\%) & $46.05 \pm 1.01$ & $45.12 \pm 0.56$ & $45.28 \pm 0.09$ & $42.18 \pm 1.06$ & $43.11 \pm 0.26$ \\
\hline $\begin{array}{l}\text { Solubility of } \\
\text { solids (\%) }\end{array}$ & $73.58 \pm 0.66^{\mathrm{b}}$ & $78.67 \pm 0.82^{\mathrm{bc}}$ & $81.64 \pm 0.56^{\mathrm{cd}}$ & $85.11 \pm 0.86^{\mathrm{d}}$ & $65.24 \pm 1.8^{\mathrm{a}}$ \\
\hline
\end{tabular}

$\mathrm{A} 1=$ gum arab, A2= whey, A3= chitosan, A4= maltodextrin and A5= zeolit

Different superscript in the same column indicate significant effect $(\mathrm{P}<0.05)$

\subsection{Effect of Treatment on Dry Matter of Microcapsule Product}

The results of the analysis of variation regarding the dry matter content of various encapsulants used to coat leilem leaves and avocado seed extract were not significantly different $(\mathrm{P}>0.05)$ to the dry matter of encapsulated products. Microwave temperature is the same, and the materials have the same physical characteristics. According to [6] showed that the different temperature of extraction and encapsulation process have significantly effect on the phenolic content, antioxidant activity and antimcrobial activity. In the $40{ }^{\circ} \mathrm{C}$ temperature was the optimun for obtained the TPC and chemical properties. The dry matter content of encapsulated products from various encapsulation types shows high dry matter content above $90 \%$ and water content less than $10 \%$. High dry material indicates that the water content in the encapsulated product is difficult to spread in water because the material tends to be sticky so that no pores are formed. The study results [7] explained that the encapsulation of probiotics with dextrin and triacylglycerol ingredients resulted in water content of $7-12 \%$. The results of this study were that chitosan and maltodextrin encapsulants showed a higher average dry matter. Therefore, microencapsulated dry matter is affected by the use of encapsulation.

\subsection{Effect of Treatment on Density of Microcapsule Product}

Data of analysis variance the encapsulant type to coat lileum leaves and avocado extract did not significantly different $(\mathrm{P}<0.05)$ on the density of the encapsulated product. The lowest 
value of density showed good density. The different encapsulants have other properties in coating leilem leaves and avocado seed extract. The differences in density in gum arabic and chitosan are because gum arabic has a more considerable molecular weight $( \pm 500,000)$ and a more complex molecular structure. Chitosan has a molecular weight of $171,790[8]$ compared to maltodextrin. Maltodextrin has a lower molecular weight (less than 4000) a more straightforward molecular structure. The density of the encapsulated product is lower than the material encapsulated because the encapsulated product and the materials encapsulated have bound to the encapsulated material. Therefore, it can be produce encapsulated particles with greater cohesion and adhesion forces [9].

\subsection{Effect of Treatment on Yield of Microcapsule Product}

Data of analysis variance the encapsulant type to coat lileum leaves and avocado extract was not significantly different $(\mathrm{P}>0.05)$ to the yield of encapsulated products. The higher yield of the product showed higher efficiency of the encapsulated product. Based on the higher number, the yield is the use of gum arabic and chitosan. This is because gum arabic, chitosan, and whey are better to be able holding the material, so the yield is increased compared to other encapsulants. Gum arabic has good emulsion-forming properties and low viscosity so that it is easy to dry and obtain high encapsulation yields. The use of gum arabic at high concentrations will form an emulsion with very high viscosity. Whey functions as an emulsifier and film-forming; whey protein has a viscosity that is not too high, making it easier for the drying process to produce dry ingredients and high microencapsulated yields. The results of this study are not in line with research [10] which stated that maltodextrin-whey $(2: 1)$ encapsulated yields more elevated than the use of arabic-whey gum $(2: 1)$ in the encapsulation process of pumpkin extract..

\subsection{Effect of Treatment on Solubility of solids of Microcapsule Product}

The variance analysis of the data showed that the type of encapsulation was significantly different $(\mathrm{P}<0.05)$ on the physical indicators of solid solubility. The solid solubility of the encapsulated product is the one with the highest solubility. Maltodextrin encapsulants have a high solubility level because maltodextrin has good solubility properties [11]. The good encapsulated product is yield, dry matter, high solubility, and low density [8].

\subsection{Effect of Treatment on Microscopic Structure}

The results of scanning the structure of the encapsulated product with black SEM can be seen in Figure 1. The results of microscopic structure observations on the leilem leaves and avocado seed extract encapsulated products showed that the treatment using arabic gum, whey, and chitosan encapsulants did not show any cavities, however, maltodextrin and zeolite show that the product has a cavity on its surface. In the SEM image, it can be seen in the encapsulation process that there are holes from the encapsulation product, which indicate structural damage to the product. In Figure 1 it can be seen that the morphological structure of the leilem leaves and avocado seed extract encapsulated products by processing using a modified microwave oven is irregular in shape. The irregular shape of the encapsulation process of a natural acidifier - phytobiotic mixture with a microwave oven is 
because in the encapsulation process, it does not pass through the spool as a shaper, unlike in the encapsulation process that uses a spray drier.
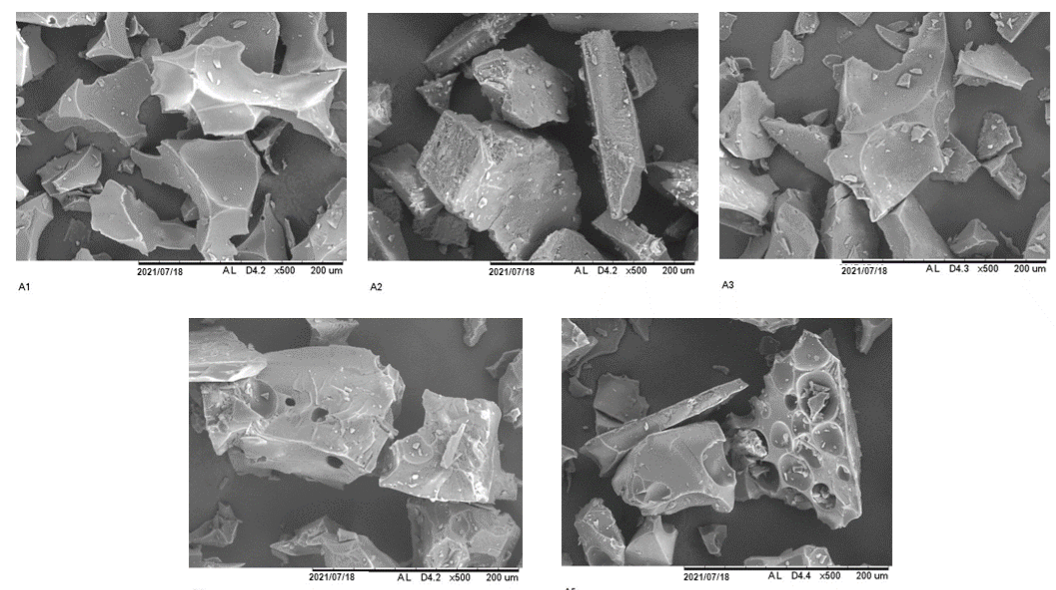

A5

Figure 1. Microscopic structure of encapsulation product with Scanning electron microscopy $. \mathrm{A} 1=$ gum arab, A2= whey, A3= chitosan, A4= maltodextrin and A5= zeolit

\section{Conclusion}

The conclusion of this research showed that the encapsulation process of the mixed extract of leilem leaves and avocado seeds using a microwave oven and chitosan encapsulation can produce the best physical quality and microscopic structure. This finding maybe can be use as the best product as a feed additive for poultry.

\section{References}

[1]. S. O.A Bontjura,. Waworuntu, and K.V. Siagian. Pharmacon Jurnal Ilmiah Farmasi 4 (4): 96 - 101 (2015).

[2]. Parubak and A. Sulu. Chem. Prog. 6 (1): 34 - 37 (2013)

[3]. I.Antasionasti, S. Riyanto and A. Rohman. Res. J. Med. Plants 11(2): $55-56$ (2017)

[4]. J. Tabeshpour, B.M. Razavi and H. Hosseinzadeh. Phytother. Res. 31(6): 819-837 (2017)

[5] M.H. Natsir, O. Sjofjan, E. Widodo, I. Ardiansah and E.S. Widyastuti. Livestock Research for Rural Development 31 (1) (2019)

[6] C.,Onyebuchi, and D.Kavaz, Scientific Reports, 10(1), 1-11 (2020)

[7] Seveline. Tesis. Institut Pertanian Bogor (2005)

[8] R. Yulina, W. Winiati, C. Kasipah, W. Septiani, A.S. Mulyawan, and T. Wahyudi. Arena Tekstil 29 (2) : 81-90 (2014)

[9] T.Rahayuni, Sutardi and S, Umar. J. Agrosains 15: 391-402 (2002)

[10] M.Gardjito, A. Murdiati and N. Aini. Jurnal teknologi pertanian 2:13-18 (2006)

[11] B.R. Bhandari, and B.R. D'Arcy. Review of Food Australia 4892:547-551 (1996) 